\title{
Evaluation of Height of Tsunami Induced by Submarine
} Landslide

\author{
Yoshikane Murakami $^{1}$, Takemi Shikata ${ }^{2}$ and Koji Tonomo ${ }^{2}$ \\ 1. Centers for Civil Engineering and Architectures, Kansai Electric Power Co., Inc., Fukushima Ward, Osaka, Osaka 553-0003, \\ Japan \\ 2. Port and Coastal Engineering Group, Newjec Inc., Kita Ward, Osaka, Osaka 531-0074, Japan
}

\begin{abstract}
Under the new regulatory requirements for nuclear power plants in Japan, which were enacted in response to the nuclear accident associated with the Great East Japan Earthquake Tsunami that occurred on 11 March 2011, it is a requirement to establish a site-specific "standard tsunami" based on numerical analysis considering non-seismic factors in addition to general seismic faults. It is necessary to establish a consistent evaluation scheme for estimation of tsunami height induced by submarine landslide, since a standard framework for evaluation has not yet been established even though several models for calculation have been proposed and applied in practice. In this study, we estimated the scale of submarine landslide from a literature survey and showed examples of tsunami height evaluation using multiple schemes. As a result of evaluation of tsunami height using three schemes, the Watts model, the KLS model, and the modified-KLS model, the result obtained by the KLS model was comparatively large for every case.
\end{abstract}

Key words: Submarine landslide, landslide-induced tsunami, tsunami height evaluation, new regulatory requirements for nuclear power plants in Japan, standard tsunami.

\section{Introduction}

In cases of tsunami induced by offshore submarine landslide, it is reported that although frequency of occurrence is exceptionally low compared with the more common seismic tsunami induced by marine fault activity, these may nonetheless on rare occasions inflict extensive damage, such as in the 1771 Meiwa-Yaeyama earthquake tsunami, et cetera. In addition, since traces of numerous offshore submarine landslides have been discovered in the sea around Japan, the possibility of future occurrences cannot be excluded. Therefore, it is expedient to consider appropriate offshore submarine landslides as a necessary factor in evaluating tsunami impacts on coastal structures, based on topographical characteristics of the evaluated site. For example, in

Corresponding author: Yoshikane Murakami, master of engineering, manager, research fields: tsunami engineering, dam engineering. the review of conformity to the new regulatory requirements for nuclear power plants, it is a requirement to establish a site-specific "standard tsunami" based on numerical analysis, allowing for uncertainties such as source location, scale and occurrence timing etc., considering general seismic faults, non-seismic factors and combinations thereof selected as the source of the tsunami.

On the other hand, it is recognized as an important issue to establish a consistent evaluation scheme for submarine landslide, since a standard framework for evaluation has not yet been established although several models for calculation have been proposed and applied in practice. In this study, we propose one consistent method of tsunami height evaluation applicable to offshore submarine landslide, based on the review on conformity to the new regulatory requirements relating to the Takahama nuclear power plant (Takahama NPP) owned by Kansai Electric Power Co., Inc. 


\section{Procedure for Evaluating Submarine Landslide Tsunami}

In the evaluation of tsunami induced by the submarine landslides in the waters surrounding Wakasa Bay in the Japan-Sea coast, we carried out the following procedure based on available scientific evidence. Tsunami height estimation was carried out in consideration of the uncertainty of the location and scale of the submarine landslide, which may have the potential for a tsunami to affect the location site of power plant.

(1) Literature survey

- Confirm the distribution of submarine landslide based on the results of a review of literature, such as the seabed geological map.

(2) Specify the features of landslide topography

- Interpret possible landslide terrain features from the submarine topography prepared by commercial digital data such as M7000 series etc.

- Interpret the marine acoustic exploration record and classify the strata based on the classification of Ref. [1]; ascertain presence of submarine landslide.

(3) Scale estimation of submarine landslide topography

- Divide the location area of the extracted submarine landslide topography with consideration of its position and orientation, and approximately evaluated by the estimated vertical cross-sectional area of the collapsed part of the landslide.

- To calculate the detailed topographic change due to the submarine landslide, interpret the collapsed part and sedimentary part of the sea bottom topography judged to be the largest submarine landslide in each divided area, based on the reanalysis of the acoustic exploration record in the relevant sea area.

(4) Tsunami height estimation

- Estimate the initial sea level distribution of the tsunami using multiple procedures.

- Calculate tsunami propagation with nonlinear long wave theory.

\section{Setting of Submarine Landslide Properties to Be Evaluated}

\subsection{Detection and Extraction of the Submarine Landslide Traces}

According to Ref. [2], a group of submarine landslide traces is shown near the Oki Trough of the Japan Sea. Also, several possible slump scarps are shown extensively around the Oki Trough in the marine geological map provided by National Institute of Advanced Industrial Science and Technology (e.g. Ref. [3]). According to the sedimentological map (e.g. Ref. [4]), the facies suspected of submarine landslides are shown around Oki Trough in the same way. On the other hand, slump scarps and facies suspected of submarine landslides are not shown in other areas.

Based on the results of these literature surveys, we ascertained the presence of submarine landslide topography by reanalysing results of high resolution marine acoustic exploration records for all sea areas around the Oki Trough where there might be a submarine landslide topography.

As a result, a total of 38 submarine landslide traces were extracted on the continental slope near the southeastern and southwestern parts of the Oki Trough, about 500-1,000 $\mathrm{m}$ in depth.

\subsection{Selection of Submarine Landslide Topographies to Be Evaluated}

The 38 submarine landslide traces extracted as a study target were broadly classified into three areas (areas A to C) depending on their locations and orientations, as shown in Fig. 1.

Here, with regard to the submarine landslide ES-G3 of area A, located in the north of Gentatsu-se (a part of the Echizen Bank Chain), Ref. [5] mentioned that "This submarine landslide trace (Es-G3) was formed by two slope failures. The collapse time is thought to be at the time of declining sea level in the last ice age, and the trigger for the collapse may have been an increase in the inclination angle due to developing anticline structure, and an increase in the supply of 


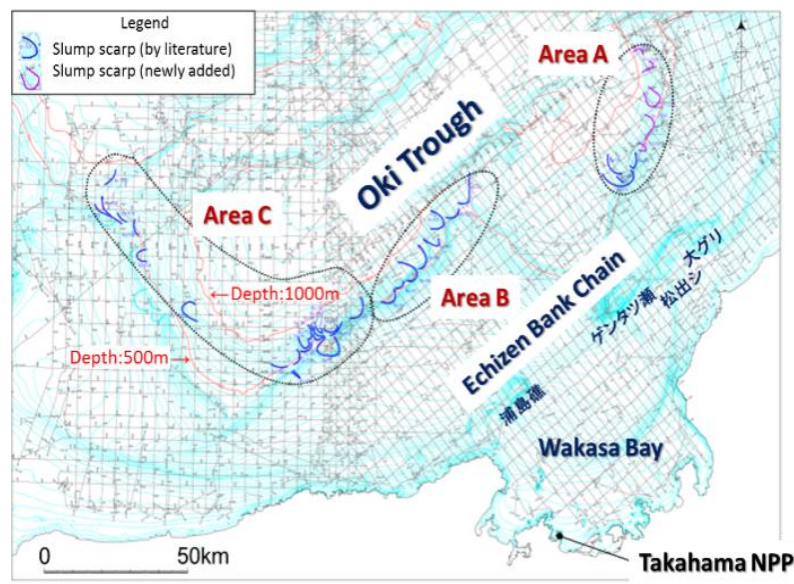

Fig. 1 Location map of 38 extracted submarine landslide traces.

sediment to the slope area." In other words, it is impossible to accurately estimate a future submarine landslide, since the geological environment around the Oki Trough is totally different from that in the past. Therefore, we decided to evaluate, for each area, the tsunami induced by the largest one from the extracted traces of earlier submarine landslides. Using this approach, we expected that we could obtain a comprehensive estimate, on the safe side, for tsunami height evaluation, even allowing for the uncertainties - the possibility that a future submarine landslide will occur on a different scale and in a different place.

Since vertical water level fluctuations have a high impact on tsunami height estimation, we considered the largest submarine landslide to be the submarine landslide topography with the largest vertical cross section of the collapsed part, estimated from the high resolution marine acoustic exploration records for the respective areas. Regarding the validity of the method of scale evaluation based on the cross-sectional area applied in this study, it is confirmed that the same landslide topography is selected as the largest scale, even in the case where the estimated volume of the collapsed part is calculated by multiplying the projected area of the slump scarp by the maximum thickness, interpreted from the high resolution marine acoustic exploration records.
Based on the above, as shown in Fig. 2, Es-G3 in area A, Es-K5 in area B and Es-T2 in area C were selected as the largest submarine landslide topography of the respective areas to be evaluated.

\subsection{Estimation of Topographic Change Caused by Submarine Landslide}

The sea bottom topography change due to landslide is estimated by the following procedure (Fig. 3) in accordance with Ref. [5] with high resolution marine acoustic exploration records, since it needs to be estimated accurately as it is considered to directly affect tsunami height.

(1) Reanalyze the high resolution marine acoustic exploration records and interpret the width, length, altitude etc. of the collapsed part and sedimentary part

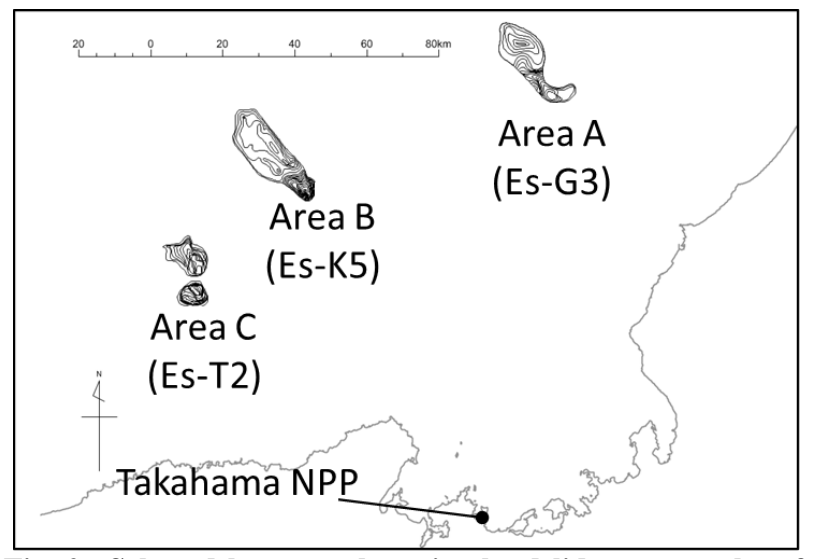

Fig. 2 Selected largest submarine landslide topography of respective areas.

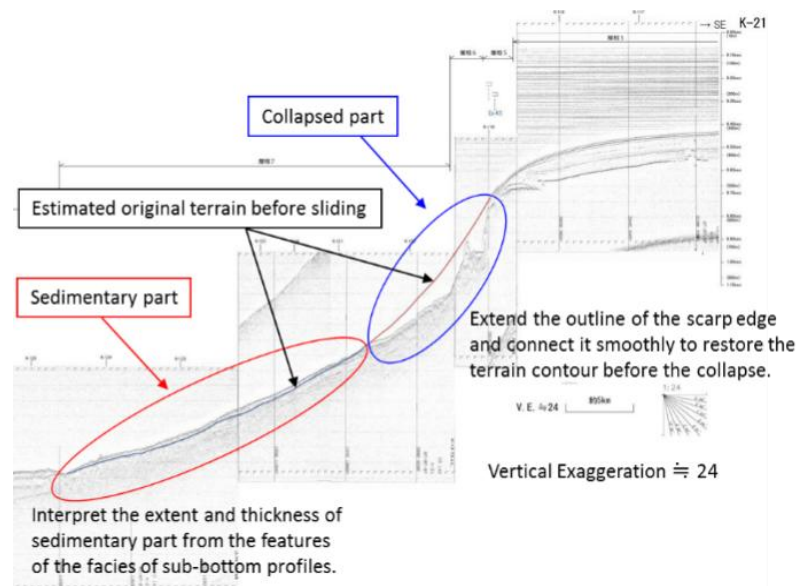

Fig. 3 Typical example of interpretation of the sea bottom topography change due to submarine landslide. 
from the features of the facies of multiple sub-bottom profiles passing through the submarine landslide topography.

(2) To restore the terrain contour before the collapse, extend the outline of the scarp edge and connect it smoothly, cross-check between each of the survey lines, and confirm three-dimensional consistency of the restored terrain contour.

(3) Considering the balance between the volume of collapsed part and sedimentary part, estimate a distribution of the volume of topographic change in the sea bottom.

Applying the above procedure on the submarine landslide of Es-G3 in area A interpreted by Ref. [5], produced substantial consistency with Yamamoto's results in the restored topography before the collapse, the distribution of the sea bottom topography change and the collapse volume, and confirmed the reasonability of the procedure. The above procedure was then also applied for areas B and C to estimate the change in the sea bottom topography. Fig. 4 shows the estimated distribution of the sea bottom change due to the submarine landslide in area $\mathrm{B}$, as one instance.

\section{Tsunami Height Estimation Induced by Submarine Landslide}

\subsection{Approach for Tsunami Height Estimation}

For evaluation of the tsunami height by the submarine landslide, tsunami propagation simulation was carried out with the condition that the initial water level distribution was calculated based on the original sea bottom topography and the collapsed topography after the landslide.

Calculation of the initial water level distribution was carried out by more than one forecasting approach in consideration of uncertainty. The KLS (kinematic landslide) model proposed by Ref. [6], and Watts model proposed by Refs. [7] and [8] were applied to set the initial condition for the tsunami propagation simulation.

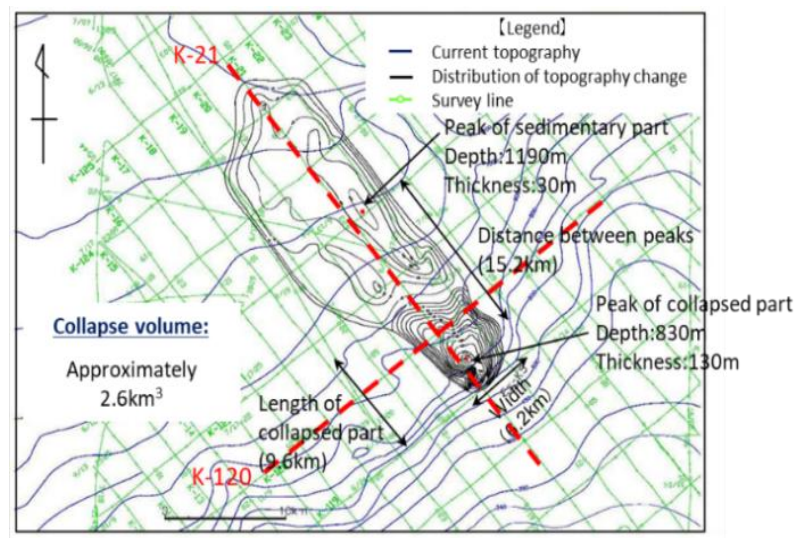

Fig. 4 Estimated distribution of the sea bottom change due to submarine landslide in area $B$.

\subsection{KLS Model}

Based on the calculation model proposed by Ref. [6] as shown in Fig. 5, the topographic change before and after the landslide is considered as propagating at sliding velocity " $U$ " from the single rupture starting point (peak of the collapsed part), and the topography change of each calculation point is considered as continuing for duration time "Tz". Next, the tsunami propagation simulation is carried out with the condition that this topographical change amount (change amount per unit calculation time) is considered as directly reflecting in the sea bottom topography and sea level.

Currently, there is no established knowledge to set the required parameters " $\mathrm{U}$ " and "Tz" in general. Therefore, in accordance with our previous study [9], we applied the maximum landslide velocity obtained by the estimation formula, shown as Umax in Eq. (1), proposed by Ref. [8] as sliding velocity "U" in this study. As for the duration time "Tz", we applied

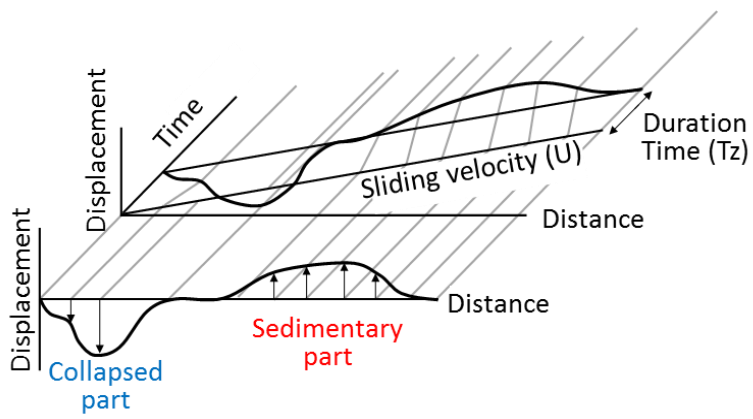

Fig. 5 Conceptual overview of the KLS model proposed. 
the calculated value obtained from Eqs. (2) and (3) based on the landslide velocity Umax so that the duration time would be the fastest in the range in which the topographic change is considered reasonable. Also, the completion time of the landslide, "Tend", can be calculated as shown in Eq. (4).

$$
\begin{gathered}
U=\sqrt{g d} \sqrt{\frac{b \sin \theta}{d} \frac{\pi(\gamma-1)}{2 C_{d}}\left(1-\frac{\tan \psi}{\tan \theta}\right)} \\
T_{Z}=D_{Z} / U_{Z} \\
D_{Z}=T / \cos \theta, \quad U_{Z}=U \sin \theta \\
T_{\text {end }}=T_{Z}+(h-d) / U_{Z}
\end{gathered}
$$

where, $b$ : length of sliding mass, $d$ : initial depth of sliding mass, $T$ : thickness of sliding mass, $\theta$ : slope angle, $\Psi$ : friction angle, $\gamma$ : specific gravity of sliding mass, $C_{d}$ : drag coefficient, $D_{Z}$ : maximum collapse depth, $U_{Z}$ : sliding velocity (vertical component), $h$ : water depth.

\subsection{Watts Model}

Whereas the above-mentioned KLS model calculates the time series change of the sea bottom topography and sea surface fluctuation simultaneously for every time unit, the Watts model is a relatively simple scheme, in that it calculates tsunami propagation by using as the initial condition the initial spatial distribution of water level due to the landslide.

To adopt the Watts model, it is necessary to properly define the initial water level distribution. In this study, we considered applying the proposed formula of Refs. [8] and [7] based on Ref. [9]. The proposed equations are shown in Eqs. (5) and (6).

$$
\eta(x, y)=-\frac{\eta_{0,3 D}}{\eta_{\min }} \operatorname{sech}^{2}\left(\kappa \frac{y-y_{0}}{w+\lambda_{0}}\right)\left(\exp \left\{-\left(\frac{x-x_{0}}{\lambda_{0}}\right)^{2}\right\}-\kappa^{\prime} \exp \left\{-\left(\frac{x-\Delta x-x_{0}}{\lambda_{0}}\right)^{2}\right\}\right)
$$

$$
\eta_{0,3 D}=\eta_{0,2 D}\left(\frac{w}{w+\lambda_{0}}\right)
$$

where, $\eta_{0,3 \mathrm{D}}$ : maximum water level decrease (three-dimensional), $w$ : width of SMF (submarine mass failure), $\eta_{\min }$ : minimum of the function on the right-hand side of (5) excluding the amplitude, $\kappa ; \kappa$ ': shape parameters $(\kappa=3)$. In addition, the parameters $w, \eta_{0}, D, \lambda_{0}$ : characteristic tsunami wave length and $\Delta x$

$\left(=\lambda_{0} / 2\right)$, which are required for the proposed equation are obtained from the result of interpretation of collapsed topography, or calculated from the prediction equation of the tsunami amplitude as shown below.

$$
\begin{gathered}
t_{0}=\sqrt{\frac{R}{g}} \sqrt{\frac{\gamma+C_{m}}{\gamma-1}} \\
\lambda_{0}=t_{0} \sqrt{g d}
\end{gathered}
$$

where, $b$ : length of SMF, $d$ : initial depth of SMF, T: thickness of SMF, $\theta$ : slope angle, $\gamma:$ specific gravity of SMF, $X_{g}$ : coordinates of the position where the initial water depth is d, $C_{m}$ : additional mass coefficient (=1), $S$ : moving distance, $S_{0}$ : characteristic distance $(=S / 2)$, $R$ : curvature radius $\left(=b^{2} / 8 T\right), \Delta \Phi$ : rotation angle (= $\left.2 S_{0} / R\right), t_{0}$ : characteristic time, $\eta_{0,2 D}$ : maximum water level decrease amount at $X=X_{g}$. In addition, the symbols of the parameters applied for the Watts model used here are as shown in Fig. 6.

\subsection{Calculation Conditions and Detailed Parameters}

Tsunami propagation simulation was carried out on the above introduced calculation schemes, applying 


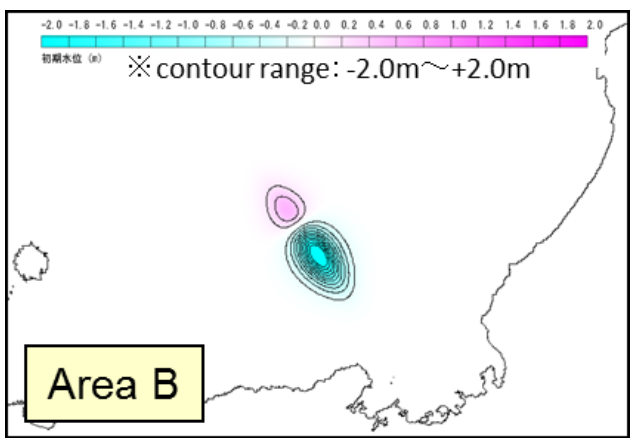

Fig. 6 Initial water level distribution of submarine landslide in area $B$.

Table 1 Parameters applied to the Watts model in area B.

\begin{tabular}{|c|c|c|}
\hline Parameter & $\begin{array}{l}\text { Submarine } \\
\text { landslide area B }\end{array}$ & Remarks \\
\hline$\gamma(-)$ & 1.4 & According to literature \\
\hline$b(\mathrm{~m})$ & 9,600 & $\begin{array}{l}\text { Length of sliding mass } \\
\text { (map-reading) }\end{array}$ \\
\hline$T(\mathrm{~m})$ & 130 & $\begin{array}{l}\text { Depth at the peak of collapsed } \\
\text { part (map-reading) }\end{array}$ \\
\hline$w(\mathrm{~m})$ & 6,200 & $\begin{array}{l}\text { Width of collapsed part } \\
\text { (map-reading) }\end{array}$ \\
\hline$d(\mathrm{~m})$ & 700 & $\begin{array}{l}\text { Initial depth of sliding mass } \\
\text { (map-reading) }\end{array}$ \\
\hline$\theta(\mathrm{deg})$ & 1.7 & $\begin{array}{l}\text { Inclination of sliding mass } \\
\text { (map-reading) }\end{array}$ \\
\hline $\mathrm{g}\left(\mathrm{m} / \mathrm{s}^{2}\right)$ & 9.8 & \\
\hline$C_{m}$ & 1 & \\
\hline$S$ & 15,200 & $\begin{array}{l}\text { Distance between peak of } \\
\text { collapsed part and peak of } \\
\text { sedimentary part (map-reading) }\end{array}$ \\
\hline$S_{0}$ & 7,600 & $=\mathrm{S} / 2$ \\
\hline$C_{n}$ & 0.086 & $=S_{0} /(R \cos \theta)$ \\
\hline$R(\mathrm{~m})$ & 88,615 & $=b^{2} / 8 T$ \\
\hline$a_{0}\left(\mathrm{~m}^{2} / \mathrm{s}\right)$ & 0.140 & $=S_{0} / t_{0}^{2}$ \\
\hline$t_{0}(\mathrm{sec})$ & 233 & From Eq. (7) \\
\hline$\lambda_{0}(\mathrm{~m})$ & 19,292 & From Eq. (8) \\
\hline$\Delta \Phi(\mathrm{rad})$ & 0.172 & $2 S_{0} / R$ \\
\hline$u_{\max }(\mathrm{m} / \mathrm{s})$ & 32.63 & $=S_{0} / t_{0}$ \\
\hline$\Delta X(\mathrm{~m})$ & 9,646 & $=\lambda_{0} / 2$ \\
\hline$\kappa$ & 0.625 & \\
\hline$\eta_{0,2 \mathrm{D}}(\mathrm{m})$ & 9.79 & From Eq. (9) \\
\hline$\eta_{0,3 \mathrm{D}}(\mathrm{m})$ & 2.38 & From Eq. (6) \\
\hline
\end{tabular}

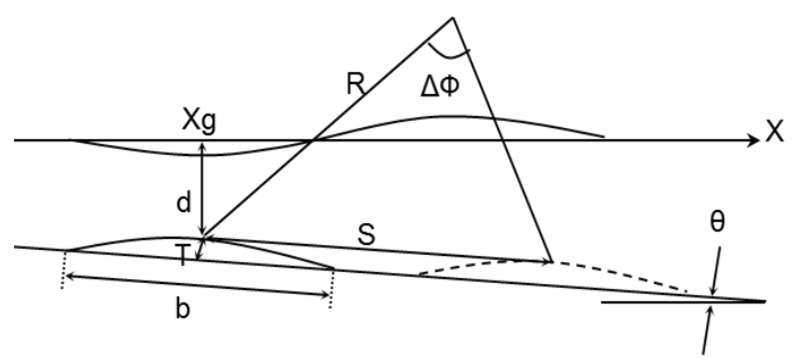

Fig. 7 Symbol of the parameters applied for the Watts model.
Table 2 Calculation conditions applied to the KLS model in area $\mathbf{B}$.

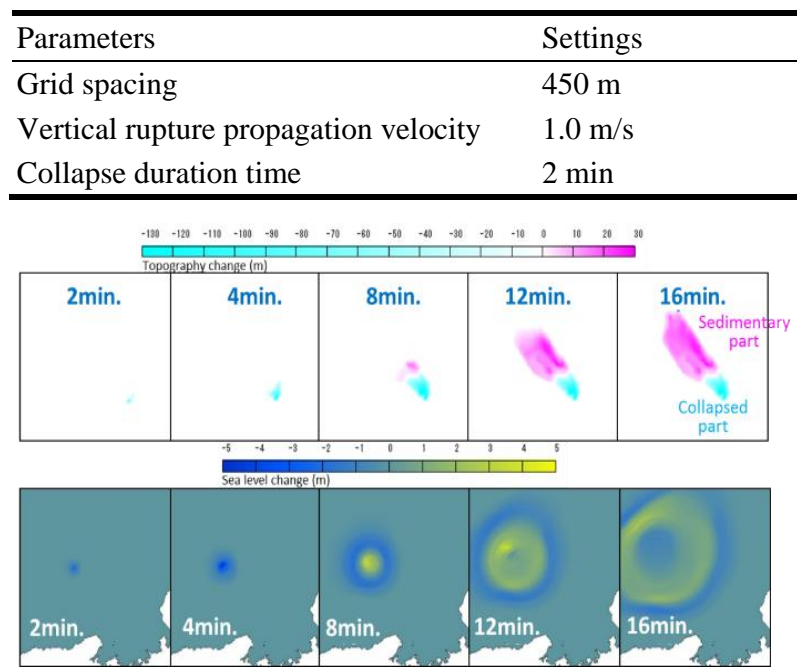

Fig. 8 Time series variation of topography change (above) and tsunami propagation (below) calculated by KLS model in area $B$.

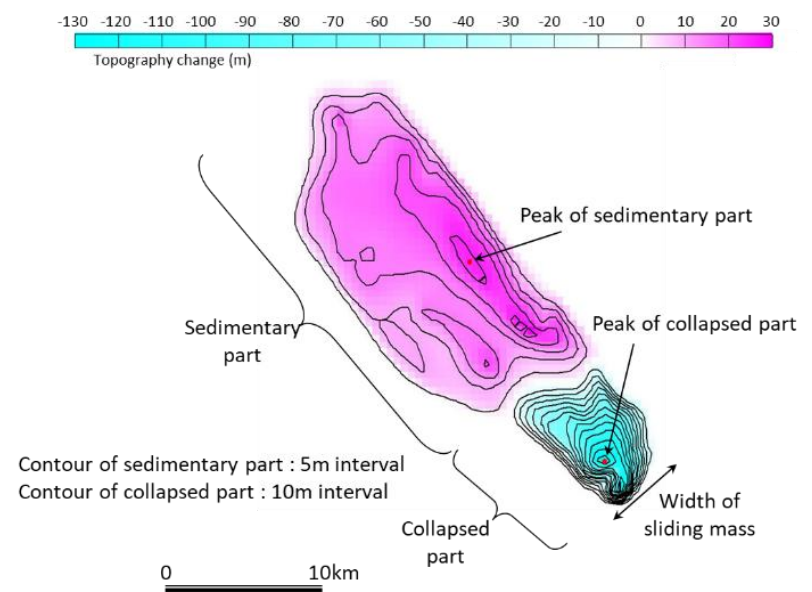

Fig. 9 Distribution of topography change amount input to the KLS model in area $B$.

the parameters of each of the submarine landslides in areas $\mathrm{A}$ to $\mathrm{C}$ established in Chapter 3. The parameters and initial water level distribution of area $\mathrm{B}$ in the Watts model are shown in Table 1 and Fig. 7. Table 2 shows the calculation conditions applied to the KLS model in area B, and Fig. 8 shows the distribution of topography change amount input to the KLS model. Fig. 9 shows the time series variation of topography change, and tsunami propagation from immediately after the topography change induced by the sliding until about 16 minutes after the topography change is completed. 
According to this, it can be found that until about 4 minutes after the beginning of the landslide, only the collapse advances, without any sedimentation, and correspondingly the water level is unilaterally depressed. The water level then begins to rise, after 8 minutes, synchronously with the beginning of sedimentation.

For each calculation scheme, the general method of non-linear long wave theory (shallow water theory) computed by differentiating the staggered Leap-frog scheme was applied to calculate tsunami propagation.

The minimum space grid size: $3.125 \mathrm{~m}$, time step for calculation: $0.05 \mathrm{~s}$, computation time: $3 \mathrm{~h}$, Manning's roughness coefficient: 0.03 , tide level for tsunami height evaluation: T.P. $+0.49 \mathrm{~m}$ (considering mean HWL for upside calculation) and T.P.-0.01 m (considering mean LWL for downside calculation) are applied as calculation conditions respectively.

\section{Calculation Result and Consideration}

The results of the tsunami height evaluation on the front of the intake of the Takahama NPP are summarized in Table 3. This shows that the evaluation result by the KLS model has a high impact on the evaluation point in both cases.

Here, regarding the validity of the tsunami height evaluation, we conducted a reproduction calculation of the submarine landslide model experiment implemented by Ref. [10] using the KLS model and the Watts model [9]. According to this, the KLS model has an excessive result of about 1.5 to 3 times the tsunami height compared with the experimental result in all verification cases. On the other hand, the reproducibility of the Watts model was good, especially in the case where the slope angle was relatively small ( $6^{\circ}$ or less). In this study, based on the slope angle of area $\mathrm{B}$ being as little as $1.7^{\circ}$, it is considered that the Watts model is more appropriate than the KLS model from the viewpoint of tsunami height evaluation.

The reason for the calculation result using the KLS model being excessive compared with the experimental result, is presumed to be that the sediment volume between the collapsed part and sedimentary part is imbalanced in the landslide duration time. In the case where the KLS model was applied to the submarine landslide, collapse proceeds until the front edge of the sliding mass reaches the sedimentary part, since a single rupture starting point is set in the collapsed part. This is due to the fact that the KLS model is fundamentally a computational model devised for tsunami height estimation induced by onshore landslide (collapse of volcanic edifice).

In order to solve this matter, we proposed the modified-KLS model in Ref. [9]. This is a model designed such that collapse and sedimentation proceed simultaneously, to keep the balance of the sedimentation volume between the collapsed part and the sedimentary part in the landslide duration, by setting the rupture starting point at two locations both in the collapse part and in the sedimentary part, where the landslide velocity applied to the modified-KLS model was set to $1 / 2$ of the KLS model from the consideration that the landslide completion time should be the same for both models. As a result, the modified-KLS model showed that the experimental results can be reproduced well from the viewpoint of tsunami height evaluation.

Based on the above findings, the calculation results obtained by applying the modified-KLS model to the submarine landslide in Area B are summarized in Table 4. According to this result, tsunami height calculated by the modified-KLS model has the equivalent result as the Watts model at both the highest and the lowest water level, and only the result calculated by the KLS model obviously became large.

It is not easy to reasonably set the landslide velocity and the rupture duration time in practice, since there are no detailed observation records of the submarine landslide, as pointed out by Ref. [9]. On the other hand, applying the sliding velocity and the rupture duration time estimated by the method of Ref. [8], it 
Table 3 Results of the tsunami height evaluation by the modified-KLS model.

\begin{tabular}{|c|c|c|c|}
\hline \multirow[b]{2}{*}{ Tsunami source } & \multirow[b]{2}{*}{$\begin{array}{l}\text { Evaluation } \\
\text { model }\end{array}$} & \multicolumn{2}{|c|}{ Tsunami height } \\
\hline & & $\begin{array}{l}\text { Highest } \\
\text { (T.P. m) }\end{array}$ & $\begin{array}{l}\text { Lowest } \\
\text { (T.P. m) }\end{array}$ \\
\hline $\begin{array}{l}\text { Submarine } \\
\text { landslide }\end{array}$ Area B & $\begin{array}{l}\text { Modified } \\
\text { KLS }\end{array}$ & 1.9 & -1.0 \\
\hline
\end{tabular}

Table 4 Results of the tsunami height evaluation.

\begin{tabular}{lllll}
\hline \multirow{2}{*}{ Tsunami source } & $\begin{array}{l}\text { Evaluation } \\
\text { model }\end{array}$ & \begin{tabular}{l} 
Tsunami height \\
\cline { 3 - 4 }
\end{tabular} & $\begin{array}{l}\text { Highest } \\
\text { (T.P. m) }\end{array}$ & $\begin{array}{l}\text { Lowest } \\
\text { (T.P. m) }\end{array}$ \\
\hline \multirow{2}{*}{ Area A } & Watts & 0.6 & -0.1 \\
& KLS & 1.7 & -0.9 \\
\multirow{2}{*}{$\begin{array}{l}\text { Submarine } \\
\text { landslide }\end{array}$} & Area B & Watts & 1.9 & -1.0 \\
& KLS & 3.4 & -3.0 \\
& Area C & Watts & 1.6 & -1.0 \\
\hline & KLS & 2.8 & -1.7 \\
\hline
\end{tabular}

was suggested that from the view point of tsunami height evaluation, approximately reasonable results are obtained by the Watts model and the modified-KLS model. Also, sufficiently safe results were considered to be obtained by the KLS model. It can be said that the evaluation scheme for submarine landslide-induced tsunami height proposed in this study is practically applicable.

\section{Conclusions}

In this study, we estimated the scale of submarine landslide from a literature survey and showed examples of tsunami height evaluation using multiple schemes. The main conclusions are as follows.

(1) A procedure was proposed to set submarine landslide properties, taking into account uncertainties of location and scale. For the evaluation target of tsunami induced by submarine landslide in the waters around Wakasa Bay, the largest landslide topography was selected in each of three areas.

(2) Two schemes were applied to calculate the initial tsunami distribution, and the setting procedure for the necessary parameter was proposed for each scheme. As a result of the tsunami height evaluation by the two schemes of the Watts model and the KLS model, the result obtained by the KLS model was comparatively large for every case.
(3) As a result of applying the modified-KLS model to the study case where the maximum tsunami height was obtained, the result obtained was almost equivalent to the result from the Watts model, and only the KLS model was obviously larger.

From the above, the KLS model, applying the maximum sliding velocity calculated by the Watts model as a parameter, was considered to provide a larger result than the other two models or experimental results. Therefore, it is considered that evaluation results on the safe side can be obtained by adopting the KLS model for evaluation of tsunami height induced by submarine landslide.

\section{References}

[1] Ikehara, K., Katayama H., and Sato, M. 1990. Sedimentological Map Offshore of Tottori, Marine Geological Map, No. 36, Geological Survey of Japan.

[2] Tokuyama, E., Honza, E., Kimura, M., Kuramoto, S., Ashi, J., Okamura, Y., Arato, H., Itoh, Y., Soh, W., Hino, R., Nohara, T., Abe, H., Sakai, S., and Mukaiyama, K. 2001. "Tectonic Development in the Regions around Japan since Latest Miocene." Journal of Japanese Society for Marine Survey and Technology 13 (1): 27-53.

[3] Yamamoto, H., Joshima, M., and Kishimoto, K. 1989. Geological Map Offshore of Tottori, Marine Geological Map, No. 35, Geological Survey of Japan.

[4] Katayama, H., Sato, M., and Ikehara, K. 1993. Sedimentological Map Offshore of Kyō-ga-Misaki, Geological Map, No. 38, Geological Survey of Japan.

[5] Yamamoto, H. 1991. "A Submarine Sediment Slide on the Continental Slope off Fukui Prefecture, Southern Japan Sea." Bulletin of the Geological Survey of Japan 42 (5): 221-32.

[6] Satake, K., and Kato, Y. 2002. "The 1741 Japan Sea Tsunami Caused by Debris Avalanche in the Toshima-Oshima Volcano." Kaiyo Monthly Special (28): 150-60.

[7] Grilli, S. T., and Watts, P. 2005. "Tsunami Generation by Submarine Mass Failure. I: Modeling, Experimental Validation, and Sensitivity Analysis." Journal of Waterway, Port, Coastal, and Ocean Engineering 131 (6): 283-97.

[8] Watts, P., Grilli, S. T., Tappin, D. R., and Fryer, G. J. 2005. "Tsunami Generation by Submarine Mass Failure. II: Predictive Equations and Case Studies." Journal of Waterway, Port, Coastal, and Ocean Engineering 131 (6): 
298-310.

[9] Tonomo, K., Shikata, T., and Murakami, Y. 2015. "Accuracy Study of Numerical Simulation of Tsunami Applied to the Submarine Landslide Model." Journal of JSCE, Ser. B3 (Civil Engineering in the Ocean) 71 (2):
I_557-I_62.

[10] Hashimoto, T., and Dan, K. 2008. "Experimental Study on Submarine Landslide Tsunami in Various Landslide Mass Shapes." Abstract of JSCE Annual Meeting 63 (2): 395-6 (in Japanese). 